\title{
Multi-Ensayos
}

Vol. 5, $\mathrm{N}^{\circ} 9$

ISSN: 2412-3285

https://multiensayos.unan.edu.ni

DOI: https://doi.org/10.5377/multiensayos.v5i9.9436

\section{El Crédito Rural y el desarrollo en Nicaragua}

\section{Rural credit and development in Nicaragua}

Róger Antonio Moreno Cruz ${ }^{1}$

\section{RESUMEN}

Recibido: 18 de enero de 2019, Aceptado: 16 de mayo de 2019

Nicaragua, según la historia, se clasifica como un país netamente agropecuario, es decir, las actividades económicas que producen la mayor fuente de ingresos y divisas para el mismo se concentran en este sector, aunque paradójicamente las cifras oficiales del Banco Central de Nicaragua presentan otro escenario. No obstante, y pese a que las cifras oficiales son correctas, debemos estar claros que esto se debe a que no ha existido estímulo por parte de los gobiernos de turno a este sector, limitándose al Comercio y la Industria. Debemos tomar en cuenta que toda actividad que genera ingresos pecuniarios, requiere por tanto de recursos financieros, los que desde el punto de vista empresarial son los más escasos y es lo que ha hecho falta para fomentar la inversión en el sector rural principalmente en los pequeños y medianos productores, los que por qué no decirlo constituyen un sector muy vulnerable en Nicaragua.

Palabras claves: crédito; divisas; gobiernos.

\begin{abstract}
Nicaragua, according to the story, is classified as a purely agricultural country, the economic activities that produce the largest source of income and currencies for the same are concentrated in this sector, although paradoxically figures officials of the Central Bank of Nicaragua have another scenario. However, and despite the fact that the official figures are correct, we must be clear that this is due to that there has been no stimulus by Governments to this sector, limited to trade and industry. We must take into account missing any activity that generates monetary income, requires therefore financial resources, which, from the business point of view, are the scarcest and is what he has done to promote investment in the rural sector mainly in the small and medium producers, that it is a very vulnerable sector in Nicaragua.
\end{abstract}

Keywords: credit; currency; Government.

1 Docente del departamento de Ciencias Económicas y Administrativas, UNAN-Managua/FAREM-Estelí. Correo electrónico: ramoreno69@yahoo.es

(c) 2019 Revista Multi-Ensayos.

(c) (1) Este trabajo está licenciado bajo una Licencia Internacional Creative Commons 4.0 Atribución-NoComercial-Compartirlgual. 


\section{INTRODUCCIÓN}

El crédito rural ha tenido de hecho a lo largo del tiempo vital importancia para contribuir al desarrollo económico y social de la población rural, por esta razón y tomando en consideración que en Nicaragua somos un país netamente agropecuario y que las principales fuentes de ingresos surgen del sector rural, en el que se encuentran inmersos pequeños, medianos y grandes productores, siendo los pequeños productores los que constituyen la mayoría es que surge el interés de esta temática.

La historia es testigo de la situación que viven los habitantes del sector rural y principalmente los que dependen del monocultivo o de la producción de productos de consumo básico, con rendimientos productivos marginales, dependientes de las condiciones climatológicas existentes en nuestro medio, afectada por fenómenos naturales que producen inundaciones y sequías que se convierten en factores no controlables y que constituyen una desgracia para los pequeños y más vulnerables que tienen que emigrar a otras zonas u otros países a vender su fuerza de trabajo por salarios de hambre que solamente garantizan el sustento diario o menos que eso.

\section{DESARROLLO}

El origen etimológico del crédito nos remonta al latín creditum, que significa "cosa confiada". Por lo tanto, la noción del crédito aparece vinculada con "tener confianza". Un crédito es una cantidad de dinero que se le debe a una entidad (por ejemplo un banco, o a una persona). En otro sentido, el término crédito se utiliza como sinónimo de autoridad, fama o reputación: “El jugador todavía tiene crédito para revertir la situación".

En el campo educativo, por lo general, en las universidades, un crédito es una unidad de valoración de una asignatura, que equivale a un cierto número de horas lectivas: "Necesito 40 créditos para poder cursar esa materia". Por último, los créditos son los títulos que mencionan a las personas que participaron en el rodaje de una película o en la producción de un programa de televisión. Suelen aparecer al comienzo o al final de la emisión. El lugar que un artista ocupa en los créditos refleja su importancia o fama; en cambio, quienes tienen participaciones menores pueden ni siquiera aparecer en los títulos. (Gardey, 2009)

El término rural está relacionado con la vida y la actividad que se desarrolla en el campo, el cuál es un espacio rico en tradiciones que configuran una forma de ser, y que definen en buena parte la cultura de las naciones, en espacios naturales y en sustento económico para muchos.

Una localidad o área, es considerada rural por su número de habitantes (densidad de población baja), menor de 2,500 aproximadamente, dependiendo de lo establecido en cada país, y por su actividad económica fundamentalmente del sector primario (actividades agropecuarias).

Esta actividad se encuentra asociada a todos aquellos procesos que impliquen capturar (pesca y caza), explotar (minería y silvicultura), cultivar (agricultura y silvicultura), y criar (ganadería y acuicultura), las materias primas sobre las cuales solo se hacen usos muy básicos.

La población rural que vive en el campo, habita en caseríos y pequeños pueblos, y se caracteriza por ser discontinua y dispersa, los inmensos espacios vacíos están destinados a la agricultura y la ganadería, actividades que cada día requieren menos mano de obra. Sin embargo, la tendencia de la población rural, es hacia la concentración de pequeños centros poblados, ya que por lo demás son muy escasos en el medio rural, son vitales para la subsistencia de la población, razón por la cual esta se ve atraída. (agrícola, 2011) 
Si leemos el diccionario de la Real Academia Española (RAE) encontramos que el desarrollo está vinculado a la acción de desarrollar o a las consecuencias de esta accionar. Es necesario, por lo tanto, rastrear el significado del verbo desarrollar: se trata de incrementar, agrandar, extender, ampliar o aumentar alguna característica de algo físico (concreto) o intelectual (abstracto).

El desarrollo también hace referencia a la definición y dilucidación de una teoría a exhibir o conversar de manera amplia ciertas temáticas o asuntos; a realizar tareas de cálculo señaladas en una expresión con características analíticas; a encontrar los términos que forman una serie o función; o, sencillamente, a acaecer, sobrevenir, o tener lugar.

Cuando el concepto de desarrollo se aplica a una comunidad de seres humanos, se refiere al progreso en el sentido social, económico, político o cultural.

El Programa de las Naciones Unidas para el desarrollo, cuya sigla es PNUD, es el organismo que se dedica a elaborar la medición conocida como Índice de Desarrollo Humano (IDH). Esta estadística que sirve como indicador del estado de una sociedad tiene en cuenta factores como la expectativa de vida saludable desde el momento del nacimiento, el nivel de alfabetización de la población adulta y de matrícula en las escuelas y la riqueza económica que se refleja en el Producto Interno Bruto (PIB).

El desarrollo económico es entendido como un proceso donde las condiciones de bienes y servicios se encuentran en estado creciente y al alcance de todos los grupos sociales que conforman la comunidad. Una sociedad donde existe un buen desarrollo económico presenta características de integración económica y social y tendría menos personas viviendo en la marginalidad. Para conseguir el desarrollo los países se guían por los principios pautados por la ONU, donde se reafirman las medidas macroeconómicas siempre y cuando estén desarrolladas en pos de una mejor producción que mejore las condiciones de vida de las sociedades.

Dentro de esas medidas brinda especial atención el desarrollo humano, que no solamente engloba las necesidades económicas, sino también las intelectuales y culturales. Por eso un país en desarrollo debería ofrecer una mejor formación a sus ciudadanos y una guía para que las capacidades adquiridas de dicha formación puedan ser llevadas a la experiencia laboral, ejerciendo una actividad eficiente en lo económico, social, cultural y político. (Gardey, 2012)

El recurso financiero reviste gran importancia en todas las actividades inherentes al ser humano, es el más escaso. En tanto las necesidades son ilimitadas y están a la orden del día.

En los años setenta existió un programa denominado "Invierno", que atendió mediante asistencia técnica y financiera al sector rural pero no todos habitantes del sector fueron beneficiados ya que el programa se revistió de sesgos políticos.

En la década de los ochenta, el programa fue sustituido por un Programa denominado Procampo con poca influencia en el sector agropecuario.

Es en esa misma década que el Banco Nacional de Desarrollo atendió a diversos sectores de la población rural concentrando el financiamiento en pequeños parceleros individuales agrupados en organizaciones cooperativas de hecho conocidas comúnmente como Cooperativas de Crédito y Servicio. Además se atendían otras organizaciones que se conformaron como Cooperativas Agrícolas Sandinistas que al parecer fueron organizaciones cooperativas conformadas bajo consideraciones legales particulares, reguladas en ese momento por el Ministerio del Trabajo. 
El acceso al crédito era fluido y se concentraba en créditos pequeños, no se realizó en el momento una supervisión adecuada por tanto los índices de morosidad obligaron al Banco a ofrecer arreglos de pago de oficio, es decir sin ninguna tramitación formal llegando en la mayoría de los casos a condonar los adeudos pendientes.

A pesar de esto y de manera muy particular, considero que en ese período hubo cierto aumento en el desarrollo rural.

En la década de los noventa estos programas de financiamiento a los pequeños productores fueron eliminados, incursiona la Banca Privada y el financiamiento se concentró en pequeña parte de la población que supuestamente era responsable, solvente y con una cultura de pago, considerando que lo más importante no es la colocación de los créditos sino la recuperación de los mismos.

Es menester señalar que en la actualidad, aunque existen programas de asistencia como usura cero, bono productivo, entre otros y que constituyen una posibilidad de desarrollo para los menos privilegiados, cuentan con muy pocos recursos, lo que dificulta la cobertura de los demandantes de estos recursos. Estos programas si contribuyen al desarrollo de la población, específicamente en el sector rural.

Debemos recordar que el desarrollo se orienta a las personas y para las personas considerando que el mismo se asocia al nivel de vida de los habitantes de una determinada área geográfica.

\section{CONCLUSIÓN}

Considerando que el recurso más escaso es el recurso financiero, el cual si hace falta, obstaculiza el desarrollo de los proyectos que tenemos previstos desarrollar, debemos recurrir a fuentes externas de financiamiento que permitan la realización de los mismos.

Tomando en cuenta además, que las necesidades de la población son ilimitadas y los recursos limitados, aunado a esto en el entendido que el sector rural es vulnerable a las fluctuaciones y políticas financieras impuestas por los sistemas de turno; y que el desarrollo está concebido por y para las personas en función de mejorar su nivel de vida, se hace necesario la implementación de organismos o instituciones que pueden ser estatales o sin fines de lucro para que atiendan al sector rural en materia financiera y que acompañen los programas de financiamiento con orientación educativa en micro finanzas adecuadas al nivel de instrucción de los sectores a atender.

\section{REFERENCIAS}

Agrícola, A. p. (2011). addac.org.ni. Obtenido de addac.org.ni: http://www.addac.org.ni

Gardey, J. P. (2009). Definición.de. Recuperado el 25 de Noviembre de 2017, de https://definicion.de/ credito/

Gardey, J. P. (2012). Recuperado el 25 de Noviembre de 2017, de https://definicion.de/desarrollo/ 